\title{
Post-Truth Politics
}

\section{Conspiracy Media and the Specter of "Fake News"}

After the midterm elections in 2014, as the Obama administration's second term wound down, the electoral calendar began looking ahead to the next election. Over the next two years one of the more remarkable presidential races in US history began to unfold, culminating on election night in November 2016 when something like a bomb went off in the American political system. Regardless of how one voted or which of the two major candidates one supported (if either), few anticipated that Donald Trump would win. ${ }^{1}$ As the professional political class, the news media, and the general public all scrambled to understand "What Happened"-to borrow Hillary Clinton's phrase-multiple interpretations emerged to contextualize the implications of a Trump presidency and forecast its impact. ${ }^{2}$ For many, it seemed to signify a radical break from the semiprogressive policies and cultural shifts around greater health-care coverage, environmental regulation, and inclusive policies and protections for the LGBTQ community. For others, it was a backlash against these same policies and a widespread reaction to the growing political clout of groups such as Black Lives Matter-confirmation that America's colonialist history of slavery and segregation was not as far in the past as many had thought. ${ }^{3}$ For still others, it signified the emergence of a new form of ethno-economic nationalism, confirmation that the further entrenchment of economic inequality was taking root around questions of race and citizenship. ${ }^{4}$ Regardless, virtually everyone agreed that something new had surfaced in American politics. With the surprise victory of President Trump to the White House, many felt that all of the accustomed frameworks and systems (journalism, democracy) were broken. Even "truth" was suspected to be in play. 
Of course, the full historical implications of this event will take many years to play out and touch on many different dimensions of American political and cultural life. Seen in the context of the preceding chapters, however, the Trump victory functions more like the fulfillment or perhaps the culmination of the larger trends around digital culture, independent media production, and mainstream politics that began in the period after 9/11. This concluding chapter will situate the 2016 election within the larger narrative threads that this book has explored. In what follows, I will examine how the Trump presidency and the shift in political culture that it signifies figure within an account of the evolution of nonfiction media as it evolved to incorporate and be subsumed by digital technology.

As the preceding chapters have demonstrated, post-9/11 political media and independent documentary both embraced digital technology in an attempt to find some novel form of expression capable of overcoming the discursive stalemate that set in with the ensuing war on terror. Be it the pervasive logic of computation in prominent documentary films (chapter 2) or the use of digital networks to facilitate film production and distribution (chapter 3 ), documentary filmmakers and their work seemed to be following a pattern that had historically played out several times before (chapter 1), even as this digital iteration led them to tools beyond the camera to produce nonindexical forms like video games, virtual environments, and data visualization (chapters 4 and 5). This period marked the moment when documentary became digital-not simply because of a material shift in production or distribution but because of a wider cultural shift in the world that these artists and activists were documenting. As early adopters who explored the limits and the capabilities of these newly emergent technologies, these media makers' digital documentaries prefigured and shaped some of the more emblematic qualities of digital culture, including a faith in data and the rapid, widespread adoption of social media.

Thus far the narrative has pursued two primary, interrelated threads. The first largely focused on the efforts of progressive activists on the left seeking to counter the apparent ascendancy of the conservative right. The second chronicled the extent to which digital technology eclipsed and enveloped virtually every other form of media. For some observers, these developments were necessarily connected, and President Obama's 2012 reelection seemed to signal a decisive victory on both fronts. It was seen by many of his supporters as proof that his first election hadn't been merely the result of an aberrant reaction to the 2008 financial crisis and was instead evidence of a larger shift toward a more progressive political environment on issues of race, foreign relations, and the role of the federal government. For others, the account of how he won was equally important evidence of the superiority of a newly decentralized and digitized approach to using data for campaigning and governing. ${ }^{6}$ Among those digital utopians inclined to interpret the material base 
of digital technology as a progressive, liberating force of individual empowerment and democratizing potential, 2012 was a victory not just for the president but for technology itself.7

Of course, this was only half of the story, and the 2016 election demonstrates just how mistaken, or perhaps premature, these conclusions were. The ascendancy of digital technology owes as much to outside historical forces as it does to any particular political philosophy. And the marginalized role of the progressive left in the aftermath of $9 / 11$ explains its prominent position in several of the preceding chapters. Political documentary has always been a tool of the opposition, whether it was opposing fascism (as it was in the '3os and '40s) or heavy-handed institutional narratives (as it was in the 1960s), championing the rise of AIDS activism in the face of official silence (the 1980s), or questioning the US government's response to an unfathomable terrorist attack after 9/11. In all of these moments, the opposition looked to new technology—be it sound, handheld cameras, video, or digital technology - as a way to revitalize the medium of documentary and counter the dominant discourse.

Rather than being an exclusive tool of the progressive left, however, digital technology and the documentary rhetoric of truth proved themselves, in 2016, to be open to any who cared to utilize them, regardless of their political leanings. Rather than a democratizing force capable of harnessing truth, digital technology proved to be a medium like any other. The demonstration of digital documentary as a medium capable of both truth and lies represents the point at which it became fully integrated within the documentary landscape. While it may have shattered the utopian hopes of some, in the context of this discussion Trump's victory completes and, in many ways, reinforces the processes that we have been following throughout. The events of 2016 are thus an important part of this story.

The problem, however, in confronting any narrative of the 2016 presidential election is that the narrative is one of multiple truths-not in a real sense, but as perceived in the minds of the electorate and expressed in the various media sources that attempted to inform and persuade it. That is, the "true" story is the presence of multiple stories, multiple levels of truth, and conflicting, contradictory versions of events. This fragmentation stems from two interlocking developments that connect to the larger ideas this book has been exploring. The first is the rise of conspiracy theory, and what I'll refer to as "conspiracy media," throughout the early 20oos. While conspiracy theorizing itself is nothing new, and not necessarily something negative, the post-9/11 period accelerated conspiracy thinking in a manner that illuminates an interesting dimension of post-9/11 political organizing, and nonfiction media more generally. This trend culminated in the election of a candidate who first gained political prominence by promoting a conspiracy theory about the legitimacy of the sitting president (Barack Obama) and his birth nation. While "birtherism" was roundly rejected in the mainstream media, Donald Trump used his notoriety as a reality television star to promote the fringe belief, thereby 
gaining entree to the political media and establishing a prominent brand of sensational notoriety that would eventually help him (in part) win the presidency. Conspiracy media within this environment benefited from and fostered greater legitimacy for themselves through the same cultural, political, and technological shifts-discussed in the preceding chapters-that benefited independent documentary. As independent media that levy strong truth claims, critique existing institutional and political power, and seek to inform and persuade their audiences, conspiracy media occupy an important (if idiosyncratic) part of the spectrum of documentary media more broadly.

The second thread this chapter will explore is the emergence in 2016 of a new species of media outlet, one that I will refer to as a "midstream media outlet." Using 2016 as a snapshot, I will explore the developments in the media landscape that produced one of the signature phrases of the 2016 election- "fake news" - and its origins in a more decentralized media landscape. Critiquing the mainstream news is, like conspiracy thinking and conspiracy media, nothing necessarily new. As chapter 3 demonstrated, the critique of Fox News was a pivotal issue in the hybrid experiments of left-wing groups like MoveOn, and Fox itself often positions its own approach as a remedy to what it calls the "biased" coverage on other networks. But in 2016, the topic became a central issue in the election. Indeed, critiquing the mainstream news became one of the signature moves of the midstream media outlets, a generation of news outlets that emerged online in the Obama years and that include names like Vox, FiveThirtyEight, Breitbart, and The Intercept. Positioned between mainstream news media and more extreme outlets on the fringe, these midsize outlets gained a prominent visibility in the 2016 election. As with conspiracy thinking, their emergence upends a great deal of the established thinking about the role of the news media and politics. Even in the context of digital media's disruptive rise across all segments of contemporary culture, news media and the nature of the industry that provides it have been radically impacted. Outlets that had existed for the better part of a century disappeared, giving way to powerful new competitors barely a few years old.

As one of the "discourses of sobriety" that Bill Nichols aligns with independent documentary film production, journalism represents a large portion of the landscape within nonfiction media more generally. Where chapter 3 was focused on questions of documentary film production and the use of digital media as a critique of right-wing news sources, and chapter 5 discussed the use of datajournalism techniques, the focus in this concluding chapter is on journalism from a more industrial, structural perspective: the nature of the news as a business and the manner in which it articulates and fulfils a role for itself within society. The rise of the midstream media outlets, and the political polarization of mainstream media more generally, have produced a new definition of what "real news" looks like-one that's increasingly influenced by the role of independent political documentary. 
Individually, these two information flows appear to be polar opposites. Conspiracy theories are, almost by definition, ideas or interpretations held by a relatively limited number of people. Their proponents seek to expose what others have kept hidden from the public. News media, on other hand, at least nominally work only from what can be demonstrably proven. Journalists seek to establish a shared basis of information in the public interest, always in search of the elusive goal of "objectivity." Where the more extreme examples of conspiracy theory might be dismissed as the mistaken fantasies of lone individuals, professional journalists aim for and usually receive a wide degree of public trust. But despite the radically different positionality of these two forms of information (one on the fringe the other in the center), they have a remarkable amount in common. For example, both conspiracy theorists and news journalists regard themselves for the most part as public servants, or at least as working in the public interest. Both also regard their work as a necessary check on the state or other powerful institutional forces in public life and seek a wide audience for the information that they provide. Finally, both to some extent regard themselves as the arbiters or at least sources of the truth about events and institutions in the world. While conspiracy media may not rise to the level of consensus media, or enjoy the same level of trust, its emergence within this same time frame illustrates and responds to the same dissatisfaction with the consensus provided by mainstream media. The formal structures in which these shifts play out-newly deployed digital tools and platforms-are the very technologies that this book has been exploring thus far.

The fates of these information sources are tied up in one another even as they reflect differing movements throughout the post-9/11 period. The fringe began moving to the center and the center began working, in some way, more toward the fringe. The space between the fringe and the center is in many ways the exact space occupied by independent documentary media, sporadically supported on one side by the larger media industry (e.g., Errol Morris and Sony Pictures) and in conversation with fringe individuals and outlaws on the other (e.g., Julian Assange and Edward Snowden). It is difficult to overstate the extent to which I do not mean these terms as some sort of judgment on the quality of either form of information. My goal here is to demonstrate the way that their mutual movement was a result of the particular political climate playing out in a continuously evolving media landscape shaped and reshaped by emergent technology.

\section{CONSPIRACY MEDIA: A THOUSAND \\ THEORIES BLOOM}

Given the tendency that Donald Trump the candidate demonstrated for associating himself with various conspiracy theories and figures like Alex Jones who propagate them, it should perhaps come as no surprise that his election generated 
an immediate explosion of conspiracy theorizing about the forces that put him there. ${ }^{8}$ As news emerged that Macedonian teenagers were fabricating news stories to generate web traffic, that a group in Russia had run political ads on social media sites promoting various fringe beliefs, that Cambridge Analytica (Trump's campaign consultant) had dubiously obtained access to profile data about millions of Facebook users, various theories began circulating that Trump's victory was the product of a conspiracy of unseen forces. ${ }^{9}$ A full accounting of either the theories that Trump himself has flirted with or those that have circled around him is well beyond the scope and purpose of this chapter, but their sheer proliferation across the political spectrum is enough to demonstrate that conspiracy thinking had come to dominate a significant portion of the political conversation. But as with so many features of the 2016 election, the prominent role conspiracy thinking played was less a new development than the culmination of trends that had been in place since $9 / 11$.

Conspiracy theories have long been an object of fascination both inside and outside of the circles who subscribe to them. Scholars working in fields as diverse as political theory, philosophy, cognitive psychology, sociology, and cultural studies have all considered different aspects of the phenomenon. ${ }^{10}$ Alongside this academic work exists a widespread market for popular catalogs and encyclopedias that describe the different conspiracy theories that exist-a depth and breadth of interest best exemplified by the publication in 2008 of Conspiracy Theory for Dummies. ${ }^{11}$ Despite, or perhaps because of, this widespread interest, the topic is one of fierce debate. The ability of individuals to formulate and hold beliefs that run counter to verifiable evidence or group consensus, the epistemological foundations and origins of such beliefs, and the relative threat to the existing status quo-or the promise that such beliefs pose for it-has led to multiple divergent interpretations. Theories about conspiracy theories seem to multiply and diverge at a pace equal to the theories themselves. ${ }^{12}$

There are, however, several points from these debates that can help orient our understanding of the prominent role that conspiracy theories played in 2016. Much of the interest in philosophy connects back to Karl Popper's contention that conspiratorial thinking runs afoul of the unintended-consequences fallacy. ${ }^{13}$ That is, conspiracy theorists mistakenly assume that political and historical events are always the outcome of conscious choices. Major events that seem to have no obvious explanation or motivation must therefore be the work of powerful unseen forces. As Popper points out, however, outcomes often run counter to the expectations of those who orchestrate their causes. While Popper's argument is cogent, and well taken among scholars who work in this area, it nonetheless fails to account for the broad variety of circumstances that seem to produce conspiracy theories. As Charles Pigden and others have pointed out, many such events are the result of intentional actions (e.g., assassinations, bombings, etc.), but the larger 
motivations or causal connections remain unknown or unspecified, and thus leave open a space for conspiracy theories to flourish. ${ }^{14}$ This thread within analytic philosophy has produced a helpful framework for categorizing and evaluating the epistemic basis for different theories and the larger logical conclusions they invite. As David Coady demonstrates, conspiracy theories can be logically justified or unjustified and factually correct or incorrect-an important distinction given the political manner in which the term "conspiracy theory" is often applied. ${ }^{15}$ As Coady and others are quick to point out, not all conspiracy theories prove to be incorrect (Watergate and the Iran/Contra affair, for example), and many that remain neither proven nor disproven may still be justified given other evidence (e.g., theories that the Bush administration intentionally fabricated evidence of weapons of mass destruction as a pretext for invading Iraq).

While this view offers a useful corrective to the traditional tendency to dismiss all conspiracy theorists as "kooks" or "weirdos", the logical and political implications of conspiracy theorizing must nonetheless be approached with care. In a foundational article from 1999, Brian Keeley claimed that conspiratorial thinking may be typically justified, and its theories are often correct, but that admitting the logical ground on which some theories are based opens the door to a corrosive chain of conclusions that make it difficult to believe anything. ${ }^{16}$ Concluding that the government has the capacity to plan, execute, and then cover up massive events like the terrorist attacks of September 11, the Holocaust, the AIDS virus, and so forth is to imagine a set of capabilities so vast that it becomes difficult to stake out a ground beyond its control. How are we, as citizens, capable of countering this level of power? This further places these types of theories in an epistemological bind: evidence that counters the theory can simply be dismissed as further evidence of the cover-up, evidence that supports it must have somehow escaped the vast powers of the conspirators, but evaluating the difference remains a fraught endeavor. Finding a logical basis to support any beliefs or perceptions in this environment, much less resist the level of control and manipulation this presupposes, places one in an untenable position.

While such frameworks provide a logical basis on which to individually evaluate the vast and expanding universe of conspiracy theory, they do not account for why they have become so prevalent, nor can they demonstrate how any particular theory fits within a larger political or cultural framework. These questions have been taken up in the social sciences and humanities, starting most infamously with the historian Richard Hofstadter's polemical essay (and later book) that first appeared in the pages of Harper's in 1964: "The Paranoid Style in American Politics." Hofstadter's use of the term "paranoid" as well as the psychoanalytically influenced style of his own midcentury writing created something of a backlash by later scholars, who criticized his attempts at "diagnosing" and pathologizing those who engaged in conspiracy theories. ${ }^{17}$ It did, however, offer enough of a history 
of conspiracy theories as well as an account of their narrative form and rhetorical style to inspire a broad body of work in response. Mark Fenster's more recent and more comprehensive analysis in Conspiracy Theories: Secrecy and Power in American Politics positions conspiracy theorizing as an outgrowth of both a welljustified cynicism toward power and an enjoyable form of interpretive, narrative analysis by the population..$^{18}$ The populist thread of many conspiracy theories can veer into fanatical and problematic territory, but it nonetheless remains a foundational element in American politics rather than a fringe reaction (as Hofstadter had positioned it). In a similar vein, Fredric Jameson has examined the emergence and presence of conspiracy logics in other mainstream cultural texts including films and television shows as a symptom of (and attempt to grapple with) the pervasive but invisible cage of late capitalist totality. ${ }^{19}$ The tendency to question the official narrative accounts provided by the government and other institutional powers was clearly a well-established force within American culture (popular and marginal, fictional and nonfictional) long before the 2016 election. It is also, of course, a tendency shared by many independent political documentary films, which have a long tradition of challenging official narratives and providing alternative points of view.

What remains less clear is the role that media play within the formulation and spread of conspiracy theory-a class of media that, as I mentioned earlier, I will to refer to as "conspiracy media." Conspiracy media comprise the various forms of evidentiary media (including government reports, documents, audio and video recordings, photographs, and other items) that connect the cultural and political impulses behind conspiracy theories with the logical frameworks in which alternative narratives are assembled and tested. They provide a nucleus around which different conspiracy communities coalesce, and function as key points of exchange between the official or consensus understanding of an event and the alternative accounts that conspiracy theorists put forth. The legitimacy of conspiracy media (authentic or fabricated, relevant or extraneous, transparent or obscure) forms the ground on which the competing realities they represent are weighed and tested. And perhaps most importantly, their presence testifies to the absent or unseen forces that by definition separate the conspiracy theory from the official or consensus narrative. Looking at these conspiracy media-what forms they take, where they originate, what they respond to, how they are interpreted-reveals the changing nature of media and the particular media environments that foster them at a given historical moment.

The essential role of conspiracy media for conspiracy theory can perhaps best be exemplified by the archetypical conspiracy case of the Kennedy assassination and its relationship to what is known as the Zapruder film. ${ }^{20}$ Abraham Zapruder was a Dallas businessman who happened to have brought his new $8 \mathrm{~mm}$ camera with him to Dealey Plaza on the day of the assassination and was filming the 
presidential motorcade when the shooting occurred. His footage provided a seemingly essential visual record for the investigation, and worked in a broader way to cement the assassination within the public imagination and the expanding visual culture of the time. Unfortunately, as a piece of visible evidence, the footage left a good deal open to interpretation. Within Kennedy-assassination theories the Zapruder footage forms a foundational ground from which nearly every narrative account of the assassination works, and this includes the official report the Warren Commission produced. By capturing the moment of the assassination, this piece of footage should theoretically provide a degree of clarity or consensus around what took place, but it has had an opposite effect. Everyone believes that this piece of moving-image media is evidence, but "Evidence of what?" remains the question. As Stella Bruzzi convincingly argues, its meaning is ambiguous at best. ${ }^{21}$ Without the Zapruder footage, and indeed without the myriad history of its ownership - who had it and when, who was allowed to see it, what they may or may not have done with it while they had it-assassination conspiracy would still undoubtedly exist, but it is unlikely to have occupied the prominent status in American culture that it has for much of the past sixty years.

The role of the Zapruder film as conspiracy media in the Kennedy assassination offers a number of points of correspondence with 9/11 conspiracy theory. As a germinal historical event for conspiracy thinking, the terrorist attacks on 9/11 are often characterized as the twenty-first-century equivalent of the JFK assassination. Both events were theorized as traumatic national events that signaled the end of a state of perceived innocence on the part of the American public, or American culture more broadly. Both also spawned official inquiries (the 9/11 Commission and the Warren Commission, respectively-the former of which, Fenster points out, was directly modeled on its predecessor). ${ }^{22}$

But if both events resemble one another in their cultural and historical significance and the official and unofficial responses that they generated, the media environments that surrounded them were drastically different. Media coverage, both amateur and official, of course exploded over the forty years that separated them. Instead of the "twenty-six seconds in Dallas" that Zapruder's film committed to historical memory, events on September 11 played out over several hours. Rather than a single piece of amateur $8 \mathrm{~mm}$ color film, many of the key moments in the 9/11 attacks were recorded live on television and through countless amateur recordings, particularly in lower Manhattan. Where the events in Dealey Plaza had fewer than a hundred eyewitnesses, viewers from around the globe spent most the day on September 11 in front of their televisions watching. To borrow Mary Anne Doane's well-known framework, we might observe that the JFK assassination as represented in the Zapruder film exists within the temporal framework of the catastrophe, whereas 9/11 unfolded in the space of the crisis. ${ }^{23}$ Paradoxically, however, this quantity of evidence did not make it any easier to comprehend or arrive at consensus on the nature of either event. Rather than 
clarifying or generating consensus about $9 / 11$, the pervasive ubiquity of media coverage and visible evidence did nothing to eliminate the spread of conspiracy theory around the event.

Taken together, these two events and their attendant media coverage demonstrate a few essential features of what I am referring to as "conspiracy media." The first dimension of conspiracy media that these examples reveal is their productive capacity to generate further media. If conspiracy theorizing is an attempt to assemble an alternative narrative account of events or institutional infrastructures within political, social, or historical contexts, then conspiracy media are in part the sources of the information and evidence they utilize to achieve this, and in part the eventual media they create to encapsulate and express these theories. ${ }^{24}$ As the various histories of conspiracy theory demonstrate, conspiracy theorists have always produced different forms of media (books, films, radio and television broadcasts) to make the case for their theories. This was particularly true with 9/11 conspiracy theory as it emerged and evolved in the accelerated information environment of the Internet and wider participatory culture of Web 2.0. ${ }^{25}$ The widely viewed documentary Loose Change, for example, was released online in 2005 and then reedited and rereleased in several different versions not only as its theories developed but also as the film garnered more attention and a larger production budget. Of course, almost any form of media (e.g., a popular film or television show) produces other media that comment upon it, which may in turn produce further media still. As scholars of participatory culture have demonstrated, fan communities have an incredibly productive capacity to expand the media universe of a given text. ${ }^{26}$ But conspiracy communities are fundamentally different from fan communities.

This difference introduces the second quality of conspiracy media, which is the oppositional, antithetical relationship they have with one another. As competing interpretations of the existing evidence, conspiracy media discount or dismiss other accounts, including of course whatever official narrative or record about a given event exists. These aren't just differences of opinion; they are competing interpretations of reality, alternative "truths" put forward that claim to be the definitive account of significant historical events. If The 9/11 Commission Report is true, then Loose Change must be false, and vice versa. This extends further to the various competing factions within the community that produce conspiracy media. The adversarial nature of conspiracy media thus feeds into their tendency to obscure rather than clarify the events they describe, which in turn generates the need to create further responses that refute the others, and so on. Fueled by the general skepticism and suspicion that characterize the conspiratorial mind-set and enacting the iterative, interpretive impulse that this suspicion generates, conspiracy media are the metastatic output of the larger conspiracy culture that produces them.

The final quality of conspiracy media that we can see at work in both of our primary examples above is that conspiracy media, unlike media in other contexts, 
tend to obscure rather than reveal the events they represent on a wider cultural or social level. This is the logical result of the first two qualities of conspiracy media outlined above: that they proliferate and replicate, and that their various iterations tend to be contradictory or mutually exclusive. Put differently, one of the fundamental qualities of conspiracy media is that they confuse rather than clarify the subjects they represent. Like the spread of doubt about the existence of climate change, the introduction of competing narrative accounts into the discussion of 9/11 or the Kennedy assassination seems to produce a broader confusion around the nature of these historical events. ${ }^{27}$ This seed of doubt seems to originate in the initial evidentiary media itself and regardless of its quantity. That is, like the $\mathrm{Za}$ pruder film, footage of the Twin Towers collapsing reveals one reality for a particular conspiracy community, and another for those outside of that community. To some extent, this greater quantity of evidence seems to have further destabilized consensus, allowing an ever greater proliferation of various accounts, both official and alternative, about what transpired and why. Although the degree of immediate versus delayed public suspicion differs between the two, both frequently stand out as among the most "popular" (that is, believed by the widest percentage of the population) conspiracy events. ${ }^{28}$

But if conspiracy media proliferate according to a perverse logic of their own and serve to further spread confusion, they contradict a certain logical supposition of conspiracy communities more generally: that they fundamentally lack critical information. When there is disagreement about some fundamental event or circumstance, it is logical to conclude that more information is needed. And where critical information is lacking, speculation will emerge. As Cass Sunstein and Adrian Vermeule argue in an influential if flawed article on conspiracy communities, many are the product of what they call "crippled epistemologies"intellectual frameworks where certain people "know very few things and what they know is wrong." ${ }^{29}$ In some ways this seems obvious. A greater quantity of evidentiary pieces (i.e., conspiracy media) will yield a greater number of potential combinations, and hence a greater number differing narrative frames in which to assemble them. Like cryptographic-key strength, an added number of variables or a longer key length makes finding the one "correct" combination more difficult among the increased number of incorrect competitors. In this sense, it is more accurate to claim that communities in the thrall of conspiracy theorizing know a great many things, even if what they collectively know is (by definition) mostly incorrect. Conspiracy communities do not suffer from a lack of information but instead from an abundance of it.

But the nature of this formulation should still trouble us. This simply isn't how information is (or at least was) supposed to work. Throughout the historical moment that witnessed $9 / 11$ and during which the war on terror was taking shape, an alternative narrative for the role of media and information and its relationship to 
truth was also taking shape. The widespread ubiquity of digital media fostered an expansion of the forms of amateur media production. Originally grouped under the heading of Web 2.0, these technologies, operating under the banner of participatory media, user-generated content, and eventually just social media, were ushered in on a wave of cyberutopianism steeped in an Enlightenment, positivist faith in the power of information and collective participation to root out misinformation and distortion..$^{30}$ This ethos is expressed not only in the much-hyped business manifestos and public-relations messaging that fueled Silicon Valley, but also in the critical reflections of, to varying degrees, figures like Pierre Levy, Chris Kelty, Clay Shirky, and Yochai Benkler. "With enough eyes," Linus Torvalds assures us, "all bugs are shallow." To be fair, there are a multitude of examples where collective effort produces substantive results (Linux and other open-source projects) and even reasonable informational accuracy (Wikipedia being the standard example cited by more-utopian scholars). The validity of these cases notwithstanding, however, conspiracy media offer an insistent and instructive counterexample.

If conspiracy media's abundance simply runs counter to otherwise valid models for participatory culture, so be it. However, it also seems to contradict the information/truth coupling of conspiracy theorists and their critics. As Sunstein and Vermeule contend, conspiracy theorists suffer from crippled epistemologies, which they define as "a sharply limited number of (relevant) informational sources." The cure, or perhaps the prosthesis, they offer for this condition is more information. In an unfortunate turn of phrase, one seemingly designed to stoke the nightmares of their conspiracy-minded subjects, the authors describe providing this cure as a type of "cognitive infiltration." ${ }^{2}$ This is a process whereby better, more accurate information is made available in order to counter the misinformation that is feeding the conspiracy theories. While most conspiracy theorists would presumably resist the idea of being cognitively infiltrated, most would also agree that more information is needed for the truth to be known. Conspiracy media, as I've applied the term here, provides a peek into the conspiracy, but it also implies that the true nature of the event remains hidden from view, contained in information invisible to the public: the hidden images, classified documents, or other media that could narrate the whole story, or reveal the whole picture. This unseen evidence is the structuring absence of conspiracy, an absence that can be addressed only by more information. Thus, for both conspiracy theorists and their critics, the answer to the problem of misinformation is more information.

Returning to Donald Trump and the wave of conspiracy media that accompanied his rise to power (both the conspiracies he put forth and those that his critics circulated about his election), we can see that their emergence is the fulfilment of a longer trend. Conspiracy theories and the production of conspiracy media were already on the rise in the 1990s, well before the tragedy of 9/11. Oliver Stone's JFK in 1991 and the Mel Gibson-starring thriller Conspiracy Theory in 1997 adequately 
bookend a decade marked by the initiation of the various Clinton conspiracies that would follow the couple through to Hillary Clinton's unsuccessful candidacies in 2008 and 2016. The more general and ubiquitous emergence of digital media in the 200os accelerated their spread. Given the paradoxical cycle that conspiracy media feeds into and off of, it is easy to see how these circumstances arose, although less so to forecast how they might subside. In a functioning democratic society, the traditional mediator between a skeptical public and its government is the journalist-an independent, professional watchdog tasked with holding the government accountable and informing the public. Unfortunately for anyone tuning in to find answers, however, the news was experiencing a crisis of its own, one complicated by the president's repeated charge that it was "fake."

\section{MIDSTREAM MEDIA AND FAKE NEWS}

With the rise of Donald Trump within Republican politics, fake news became a topic in the news. The evolution of its prolonged news cycle unfolded in several stages, not unlike the various stages of grief popularly associated with a traumatic loss of some sort. The concept first emerged (or reemerged) on November 3, 2016, just days before the election, when Craig Silverman and Lawrence Alexander reported the somewhat shocking news in BuzzFeed that Macedonian websites were publishing false stories about the various presidential candidates in order to generate web traffic and hence Google ad revenue for their creators. ${ }^{33}$ Trump himself then used the term in December of that year to refute claims that he would remain on as executive producer of Celebrity Apprentice during his presidency. In the first year of his presidency, he went on to use the phrase "fake news" in over 150 different tweets, although, as Steve Coll points out, the designation unsurprisingly has very little relationship to the veracity of the news story to which he attached it. ${ }^{34}$ This, along with Kellyanne Conway's use of the phrase "alternative facts," ushered in a wave of scandalized outrage and denunciation, before moving on to a further chapter of grief and mourning. This stage was marked by ponderous handwringing over the end of truth as a category of human knowledge, and was of course accompanied by a related process of pointing fingers and assigning blame. ${ }^{35}$ As this "new normal" settled in, we entered the last stage, acceptance, which was characterized by a repeated assertion that "fake news" is old news, and has a long history that dates back, in some formulations, to Plato's Republic, and at least as far back as the widespread emergence of print news in the nineteenth century. ${ }^{36}$ As long as there has been nonfiction media, it seems, there has been a means of fabricating this nonfiction as well as a degree of concern over our collective ability to decipher the difference.

Fake news may indeed be very old, but it can nonetheless point us to what's new in the new media landscape in which it is has most recently taken root. Within 
the debates over the role of "fake news", stories also began circulating about various tools and software programs capable of easily manipulating live video and audio footage. Dubbed the "next frontier in fake news," tools such as Retiming and Lyrebird seem to have replicated the crisis of confidence that still photography experienced with the advent of programs like Photoshop several decades ago. ${ }^{37}$ While there is undoubtedly a technological component of fake news, most of the examples discussed above (from the Macedonian stories on through those labeled by Trump) were relatively low-tech, pointing to the primarily cultural component of the problem. However misplaced, such anxieties do reveal a surprising degree of ongoing faith in the power of optical media to transparently and objectively record events before the lens of a camera. Simply put, the possibility of faked footage implies the possibility of real or objective footage from which it deviates, a potential long debunked by scholars of the documentary image. Moreover, the emphasis on the truth or falsity of visible evidence itself overlooks the extent to which even unaltered or "raw" footage arrives heavily mediated by virtue of the source that produced it and its motivations for doing so. These factors may enable tenuous distinctions between categories like news and advertising, documentary and propaganda, but often remain invisible under the transparent glare of movingimage evidence.

Part of what the fear over fake news activates is a deeper fear of or mistrust in the influence of media to direct public opinion. As students of media studies will immediately recognize, however, these fears are long-standing, and in fact historically synonymous with the emergence of media itself. Indeed, the rise of mass broadcast technology in the early twentieth century coincided with deep fears about its use to promote what was then being newly referred to as propaganda. As Mark Crispin Miller points out, the term "propaganda" etymologically takes on its current political and social connotations in the aftermath of World War I, when it was revealed that public opinion on the Prussian aggression of the so-called Huns leading up to and during the war was a result of specific interventions by the US and British information offices. In essence, people felt they had been brainwashed into the war by the government. By World War II, however, this fear had been redirected toward the German use of media production as part of what was increasingly characterized as a technological "war machine."

One of the supreme examples that illustrates this political polarization can be found in Frank Capra's 1940 film series Why We Fight. This series of information films was intended to inform soldiers, and eventually the general public, about the nature of the Axis war machine. While Capra made sure to include plenty of images of marching soldiers and powerful munitions, one of the primary tools that formed the enemy arsenal in his depiction was its use of broadcast technology to spread misinformation. This fear of Nazi media found ready purchase because a widespread popular perception had emerged over the prior two decades that 
broadcast media such as radio and multimedia forms like film (which combined sound and image) were capable of manipulating the public and brainwashing them through the use of invisible radio waves and provocative, agitational moving images. This popular paranoia functioned as a mode of what Charles Acland refers to as vernacular critique. ${ }^{38}$ But in Capra's conception, this fear around the power of technology was reshaped to focus on a fear of what political ends it was applied to. Its ability to manipulate the public wasn't disputed. What separated lies from truth wasn't to be found in the medium itself but instead in the politics that drove it. Like the Soviet montage theorists Dziga Vertov and Sergei Eisenstein, the powerful impact of media on the audience was a feature, not a bug. What separated good media from mere propaganda was a question of one's political position, and the designation thus became a label that was used to differentiate the enemy's use of the media from one's own. ${ }^{39}$

These traditional nonfiction categories (news, propaganda, documentary) have become increasingly complicated in the flattened digital-media landscape that has emerged online over the past two decades, reaching an acute crisis point in the fake-news debates of 2016-17. Rather than an alteration in the materiality of moving-image technology from analog to digital technology, this crisis originates in the uncertainty generated by the shifting political economy of the media market enabled by digital technology. Two particular manifestations of this evolution can help illuminate what is ultimately a broader shift. The first is the general democratization and widespread adoption of the tools of news manipulation-a practice commonly referred to as "public relations." The second is the emergence of independent, midsize news outlets like Glenn Greenwald's The Intercept or Nate Silver's datacentric FiveThirtyEight, among others. While these outlets offer a useful corrective to the corporate-dominated univocality of the "mainstream" news, their emergence over the last several years overturns several of the commonly held critiques of the mainstream media that have guided media studies scholars for the past several decades. They also, in part, feed the adversarial environment in which the suspicions around "fake news" were able to take hold.

News and documentary film both traditionally occupy adjacent positions on one part of the nonfiction landscape-a landscape that, as scholars of documentary have long pointed out, stretches across an amazingly wide variety of forms, contexts, and creators. It includes the types of amateur media production with limited distribution that we more commonly refer to as home movies and family-photo albums, as well as the vast swath of zero-degree video recording used for simple archival and broadcast purposes. ${ }^{\circ}{ }^{\circ}$ Here I'm referring to things like TED talks, university lectures, training videos, industrial films, and so forth-texts that are "true" simply because they offer an approximate record of an event. It stretches, further, to institutional contexts like surveillance videos and photos, mug shots, the ID photos on things like passports and driver's licenses - records that are "true" in an 
institutional regime of governmentality because the facsimile of people and events furthers and enables a level of control and regulation, as loaded and biased as these supposedly objective records might appear.

Within this spectrum of nonfiction material, the lines within and between these various forms of journalism and documentary and related fields like advertising and public relations are fuzzy. ${ }^{41}$ In a sense, journalism, documentary, and advertising all attempt to use the media to alert the public to events or information in their interest. All of them are true in a loose way, but we divide them into different categories for good reason. The makers of a given product believe, to some extent, in the claims they make for it, even if the wider public may not be convinced, and an established set of laws and standards holds them to account for the claims they make. In the formulation of scholars like Roland Marchand, advertising is an attempt to persuade the public to take a specific action (buy this product), whereas news is (at least traditionally) intended to inform the public about a given set of issues that may have many different possible interpretations or observations. ${ }^{42}$ Documentary, in most theorizations, sits somewhere in the middle, advocating for a specific position or course of action but not necessarily directly tied to a commercial outcome in the same way that advertising is.

Within this same landscape sits the field of public relations, or PR, as it is more commonly referred to. Public relations is the attempt to transform advertising into a form of news, or to steer the public discussion and perception of an industry or product toward a particular position or opinion. Like journalists, early pioneers in the field claimed that their work was performing a valuable public service: alerting individuals within the community to new products, services, or community developments that they might have otherwise missed. As Stuart Ewen describes in his monumental history of the field, "The rise of public relations is testimony to the ways that institutions of vested power, over the course of the twentieth century, have been compelled to justify and package their interests in terms of the common good"-even if this common good was not at first apparent to the public itself. ${ }^{43}$ In orchestrating the alchemy that might transform advertising into news, PR inherently destabilizes already porous categories, thereby creating suspicion around the role that news plays for its audience.

The man considered by many to be the "one of the most influential pioneers of American public relations" was, of course, Edward Bernays. ${ }^{44}$ Bernays, who passed away in 1995 at the age of 103, was a distant relative of Sigmund Freud-a relationship he seems to have implicitly put to good purpose in his own work. Beginning in the 1920s, he pioneered the practice of framing corporate goals and sales targets as events of public interest, finding connections between the two in order to garner free publicity for his clients. As the title of Crystalizing Public Opinion subtly implies, Bernays saw his own work as an instrumental corrective to the sort of intellectual labor and propaganda that Walter Lippmann had theorized was so 
essential and so corrosive to the working of a democracy in his own Public Opinion. Throughout his three books, Bernays's work comes across as an interesting mix of intellectual self-justification and crass self-promotion, the marriage of which was to be one of his singular, if dubious, achievements. ${ }^{45}$ While PR consultants might have worked in the interests of their institutional clients, they nonetheless thought of themselves very differently from advertising agencies. As Bernays is quoted in the introduction to his landmark text, Crystalizing Public Opinion, public-relations men don't work in images (like their advertising counterparts) but instead "deal in reality." ${ }^{66}$ This connection between image and reality, the attempt to interweave and mold both, is essential to understanding the connections between news, visual culture, and truth that fake news entails.

A comparable work written nearly a century later by the provocateur and inheritor of Bernays's mantle, Ryan Holiday, demonstrates the extent to which the manipulation of journalism and public perception has and has not changed in the intervening century. Holiday was a self-taught marketing consultant who worked with several high-profile if controversial clients including American Apparel and the author Tucker Max, eventually building a list of blue-chip corporate clients. In 2010, Holiday published Trust Me, I'm Lying, a tell-all about his methodology for manipulating the structure of the news industry. The book set off a minor controversy in media circles-an achievement he claims was intended to make the book self-exemplifying or meta-evidence of the methodology he utilized on behalf of his clients. ${ }^{47}$ The book is thus one part media critique, one part how-to on media manipulation. Holiday's method is rather simple. He claims that the news industry is a deeply hierarchical structure where lower-tier blogs and social-media figures provide the content and fodder for publishers higher up the food chain in exchange for traffic and attention. The arrangement is informal and unwritten but, in Holiday's formulation, entirely predictable. Items that get attention at one or two lower-tier venues can be used to push higher-tier venues into coverage. For example, in the campaign for the Tucker Max movie I Hope They Serve Beer in Hell (Bob Gosse, 2009), Holiday purchased intentionally provocative billboard space around Los Angeles. He then defaced these ads, took photos of the vandalism, and e-mailed them to a local culture website as evidence of the controversy the movie was generating. Once the blog picked up this story and ran it, this coverage, along with the original photos, was then sent to higher-tier publishers, with a demand to know why they were ignoring what was becoming a movement to ban the film. And so on. Holiday in essence had pioneered, or at least claimed to pioneer, the sort of manipulative tactics that right-wing provocateurs like Milo Yiannopoulos and others would master. Put differently, Holiday had figured out how to use the type of trolling tactics that Whitney Phillips meticulously documents in This Is Why We Can't Have Nice Things in the service of promoting his commercial clients. ${ }^{48}$ 
While Holiday demonstrates an essential historical continuity with Bernays in his attempts to influence the media, he is also evidence of a radical difference in the media landscape of our current moment. Both Bernays and Holiday share a certain methodology: package the interests of a specific constituency (often a corporation or industry) in a way that makes it legible to the public-and more specifically, to journalists - as legitimate news within the public interest. But Bernays is clearly a man of institutions and the elite. He represented an industry, founded a council, and consulted with the institutional leaders at the highest levels of government, academia, and industry. Holiday, on the other hand, is far more of an individual, neoliberal player. His intended readership is not the intellectual elite, or even the individual of public opinion, but instead the individual who might be able to perform a type of armchair public-relations campaign for whatever pet project or product he or she might have to hand. Rather than laying out or attempting to establish an intellectual framework that might justify the role that public relations plays in American life as his predecessor had, Holiday instead offers us a confessional tell-all on the manner in which the blogosphere might be manipulated in order to achieve viral traffic and public notoriety. ${ }^{49}$

While it is tempting to dismiss Holiday's work for what it is (a straightforward attempt at self-promotion), we should also account for the acute critique that he offers of the economic structure of the blog-driven media landscape. In ruthless detail, Holiday delineates the metrics that drive blogs like Huffington Post, Tech Crunch, Weblogs Inc., Gawker, and countless others to underpay their writers on a per-story basis predicated on the traffic that those stories generate. These working conditions force writers to search for prepackaged, sensational content in order to churn out stories that achieve viral traffic levels. Since these same realities exist up and down the hierarchy of the media structure, even the largest, most reliable news sites depend in some way on the groundwork carried out by lower-tier, less reputable players in the food chain. These are the economic realities that drove Macedonian teenagers to create absurd news stories, Facebook to ignore the viral contagion across its network as people "liked" and shared the stories, BuzzFeed to cover the emergence and influence of completely fabricated news, and an endless stream of high-profile media outlets to pontificate on the ongoing presence of truth in our current moment. At each stage of the process, traffic and attention were the key metrics that drove the proliferation of content, until eventually traffic and attention became the content.

This may seem far afield from the discussion of documentary and digital media that has dominated the discussion thus far, but we should recall that the same forces in play here (greater access to the tools of content creation, suspicion of official accounts, political polarization) are what have driven both the alterations in the news landscape that are being described here and the widespread experimentation in documentary form that was described in preceding chapters. The economic 
realities of journalism are nothing new, but in the past these forces colluded to produce the norms and standards that the specter of fake news seems to threaten. In the United States the history of the news is driven by changing relationships between advertisers, journalists, and readers. As Marchand demonstrates, many of the early newspapers and magazines self-consciously crafted their content in order to assemble the audience that they thought would appeal to different advertising demographics. ${ }^{50}$ Qualities like "truth" and "objectivity" became self-conscious ideals that were seen to appeal to a specific, well-heeled demographic that was desired by advertisers. The idealized model of journalism that emerged through the efforts of early newspaper titans like Joseph Pulitzer sought to maintain a strict boundary between the editorial positions of its publishers, the news it produced, and the advertisements it ran in support of the enterprise more generally.1 For Pulitzer these distinctions were aimed at increasing circulation: creating a product that people would trust was a means of assembling an audience that could in turn be sold to advertisers. Along with the rise of the Associated Press style as the default tone for news coverage, an amorphous notion of truth and objectivity became the default ideal in American print journalism, even if there were many critics who pointed out how distant or impossible this ideal was. As broadcast media (first radio, then television) emerged, this same basic equation between content, funding, and audience was further elaborated through the mandate that this content should be in the public interest and regulated through broadcast licensing..$^{52}$

This is not to say, of course, that news (in any of these forms) had achieved objectivity or truth. The equation on which it rested, paid for by advertising but produced in the public interest, was always an uneasy if not contradictory compromise. This inherent conflict has provided a nucleus for a great deal of media and communications research in the post-World War II period, beginning with early Frankfurt School work on the culture industry, and resurfacing in various arguments and key texts over the past fifty years. Consider, for example, Daniel Boorstin's much celebrated The Image: A Guide to Pseudo-Events in America, which analyzes the impact of visual culture on journalism as simultaneously cementing a notion of visual objectivity while playing to the basest, most sensational appetites of the audience in order to command their attention. ${ }^{53}$ Or Edward Jay Epstein's equally central News from Nowhere, which vividly chronicled the production of network news coverage and the competing demands that it satisfied (advertisers, ratings, regulators, and, of course, the audience). ${ }^{54}$ Other work, like Manufacturing Consent, by Edward Herman and Noam Chomsky, demonstrates that the illusion of objectivity invests the media with a powerful ideological capacity that overwhelmingly benefits the financial and political interests that shape it. 55 Further, the long-running concern over increased ownership concentration (the number of different media corporations that produce the news) also positions the business of media production against the quality of the information it provides. ${ }^{56}$ 
But even the most trenchant critiques of the news and its failure to achieve objectivity subtly reinforce the notion that this is the standard to which it aspires. Truth and the public interest are held throughout as the norm from which the media and journalists deviate. And, more importantly for my purposes here, it is the perceived failure to meet these ideals that became the basis of the charge of "fake news." We can see the contours of these competing forces if we consider the role of the news in covering the 2016 election. The phenomenon of Donald Trump as a candidate posed a conflict for news organizations: on one hand, his critics were predicting that his presidency would be a disaster. On the other hand, covering the disaster in progress produced record-breaking ratings for news organizations that had been under threat of consolidation and retrenchment for much of the period between 2000 and 2015. This conflict of interest was clearly expressed in a speech by the former CEO of CBS, Leslie Moonves, when he stated of the network's coverage of Trump's campaign, "It may not be good for America, but it's damn good for CBS." ${ }_{57}$ This was also the same set of forces that had apparently driven the creation of the Macedonian news stories: outrageous information generated traffic, if not truth. Once again, the public interest appeared to be at odds with the business of journalism.

But the 2016 election cycle also demonstrated the increased influence of midstream media outlets. Sites such as Vox, FiveThirtyEight, Breitbart, The Intercept, Quartz, Slate, and Axios had positioned themselves midway between mainstream news and more-marginal independent bloggers and fringe news sources. While these were the most prominent, many more also appeared in specific vertical-content categories. ${ }^{58}$ Many of them, in an effort to generate trust in readers and attract top-tier talent, are connected with or headlined by veteran journalists who once worked with older mainstream media outlets. Many employ techniques that are dependent upon or critical toward the practices of traditional mainstream journalists. And several of them are independently funded by wealthy individuals as ideological or political projects. Rather than producing consensus, these various outlets instead seem to respond to the polarization and dissensus that so characterizes the environment in which they emerged.

As an illustration of this, we can briefly compare two midstream outlets: Breitbart and The Intercept. On the surface, each resembles the other, and both fit the midstream model described above. The Intercept is largely backed by Pierre Omidyar, the billionaire founder of eBay, through an umbrella media project he started called First Look Media. ${ }^{59}$ The founders of the site-Glen Greenwald, Laura Poitras, and Jeremy Scahill-all came from existing careers in media and journalism, listing among their credits Salon, The Guardian, Democracy Now, and the New York Times, although Poitras was best known as an independent documentary filmmaker. Similarly, Breitbart was founded by veteran blogger and Fox News commentator Andrew Breitbart and heavily funded by the Mercer Family 
Foundation. ${ }^{60}$ After Breitbart's death in 2012, Steve Bannon became executive chairman and worked on revamping and expanding both the website and the organization itself. Ideologically, the two sites could not be further apart. Under Bannon's leadership, Breitbart positioned itself as a platform for the far right and "altright," openly supporting extreme conservative political issues and candidates, including Donald Trump. The Intercept, on the other hand, is largely considered liberal or left-leaning, although it would balk at any political affiliation. Both sites position themselves as correctives to the failings of the mainstream news. For The Intercept, this takes the form of what it calls "adversarial journalism," pointed at the traditional sources of power, including older, established media like the New York Times. ${ }^{61}$ For Breitbart, it means countering what it perceives to be the liberal bias in most mainstream media. What is striking about both is the extent to which their shared qualities (independent funding, a critical stance toward mainstream media and other sources of power, argument-driven information) are qualities that might equally describe a particular iteration of documentary film itself. Indeed, it is not a coincidence that figures like Scahill, Poitras, and even Bannon had, in other contexts, turned to documentary in order to accomplish what they now turned to journalism to achieve.

The evolution of these midstream players and their "adversarial" relationship with their competitors is the latest development in a longer chapter in the history of the news. Beginning in the 1990s, the rather stable landscape of mainstream journalism, consisting for decades of print media and the major broadcasts networks, was invaded by newcomers from cable, radio, and eventually the Internet. But rather than unifying mainstream media's homogeneity, each new voice positioned itself as an essential antidote to some key deficit in the existing sources of information. Thus, $\mathrm{CNN}$ was the answer to the limited amount of time allotted to news by broadcast networks, Fox was the answer to the liberal bias of CNN and others, MSNBC was a response to Fox's overt right-wing bias, bloggers were the answer to the class of professional journalists, and so on. ${ }^{62}$ Each new entrant to the increasingly competitive news marketplace-itself newly marketized as a result of media consolidation and shifting revenue sources within older, established forms like newspapers and broadcast networks - thus joined the mainstream by critiquing its existing framework and positioning itself as a better instrument of truth and objectivity. This market-driven sense of distrust also came amid cogent critiques of mainstream media practices from figures like Jon Stewart, Steven Colbert, and even The Onion, attracting large audiences while delivering well-justified outlines of mainstream media's shortcomings.

This reaches something of a crescendo in the emergence of midstream media. All of them position themselves in some way as the antidote to what's wrong or what's lacking in mainstream media. Five ThirtyEight prides itself on its data-driven journalism, and the manner in which objective data might counter the affective, 
subjective impressions of reporters that plague traditional journalism. Vox is the explainer news source, giving the story behind the stories that other news outlets take for granted. Breitbart and The Intercept are both independently funded, hence not reliant on traditional advertising revenue. Each of these outlets vies for our attention by offering us not just an additional source of information, but a "better" source of information. There is not necessarily anything wrong with a broader variety of voices. Media consolidation (i.e., fewer unique voices) has long been a primary concern among scholars and media watchdog groups. ${ }^{63}$ But this greater heterogeneity does provide an outlet, or perhaps an alibi, for those seeking to dismiss information that conflicts with their own opinions-a move implicitly or explicitly encouraged in an adversarial environment haunted by the specter of "fake news." The marketplace logic that governs the circulation of ideas and information within a democracy dictates that more ideas, more voices, are ultimately better for the individuals who make political choices based on this data. But the market logic that drives news outlets to compete for viewers through product differentiation based on the critique and dismissal of one's competitors seems to produce the opposite effect. As Yochai Benkler and his collaborators demonstrated, followers on both sides of the political spectrum in the 2016 US election were consuming a diet of media that came from across the political spectrum, but were consuming that information differently. Framed, reframed, and shared to one's network on Twitter and Facebook, these stories simply amplified or reinforced the opinions and input that one already possessed. ${ }^{64}$ A broader diversity of media sources like the one provided by the midstream outlets, built on the premise that something is lacking in the news more generally, seems to produce dissensus and suspicion rather than consensus and trust in the media.

This broader diversity of media outlets also makes any level of brand recognition more difficult. Consider, for example, beyond the relatively larger midstream choices discussed so far, the broad array of choices and sources that confront users of digital news aggregators like Instapaper, Flipboard, Google News, and Apple News. These apps enable users to choose from and curate a broad diversity of sources, potentially enabling them to explore a variety of voices from across the increasingly politicized news spectrum. ${ }^{65}$ Several studies have further demonstrated that these apps are also beneficial for news providers, bringing in additional readers who might not have been part of the existing audience. ${ }^{66}$ While the experience of browsing such aggregators seems intended to remediate the experience of browsing titles at a newsstand in the analog era, the digital form dissolves any of the material indicators that might be used to judge the quality of a source's content. When getting something into print or even into a professionally produced website required vast resources, the mere presence of a news source spoke to some level of investment and commitment. This is no longer the case, and rather than a few trusted sources that one has tested over and over through years of consideration, 
we instead have an endless sea of choices and newcomers, all of which appear to be equal, at least on the surface. This makes for a deeper level of confusion about what's real or fake, trustworthy or unreliable. The diversity of sources provides the perfect camouflage for one site to slip in among the others, imitating the trappings and aesthetics of more-established sources in the way that The Onion or the Macedonian news sites did.

This sort of camouflage through imitation in the context of information density is what enabled the alleged disinformation campaigns that appeared on social media sites including Facebook, Twitter, and Instagram. In the midst of investigating potential Russian interference in the US election, the social media platforms provided a congressional committee with examples of the various propaganda. ${ }^{67}$ Of what were purported to be thousands of advertisements purchased by these groups and paid for in rubles, fourteen examples were provided as a representative sample. As a whole, the aesthetics of these ads are fairly consistent, working to seed and spread the sort of viral, meme-driven media that already readily circulate in political channels across the web. Most seem to provide an alibi for their informal, unpolished look by pretending to be the work of amateurs and small grassroots organizations. To borrow Paul Arthur's term, this sloppy aesthetic is part of the rhetoric of authenticity, much in the way that shaky handheld camerawork connotes a type of amateur, documentary production. ${ }^{68}$ Ideologically, they are all over the map, espousing contradictory and in some cases incomprehensible political positions, but all benefitting from the sort of oppositional, adversarial environment that predominates in this same mediascape. As their metadata indicate, none of them were seen by that many people, but most were shared forward multiple times beyond their original placement, making any assessment of their audience, and hence their impact, a near impossibility.

These advertisements thus offer a sort of stand-in or emblem of the larger environment of misinformation and disinformation, paranoia and suspicion that pervades any understanding of the US election in 2016. Their material plasticity, somewhere between advertisement, propaganda, and journalism, circulates in a space of unknowability: seen by an unidentifiable audience and produced and paid for by the same. Hidden within a much larger environment of media heterogeneity that feeds on critique and suspicion, they offer a marked contrast with the efforts at mass persuasion and propaganda at work in prior historical moments, representing instead the diffusion of media within a networked space. Purchased for small amounts of money, they seem to have slipped in unnoticed among everyone else on the back of a platform whose only logic is the exchange and monetization of content created by others. But like the forms of propaganda considered earlier, this is a feature of social networks like Facebook, not a bug.

Ironically, the emergence of all of these imitators, both real and fake, satirical and earnest, seems to have produced a positive outcome for the mainstream, 
traditional targets of their attack. Since the 2016 election and Donald Trump's one-man war on the media, many of these older news outlets have been asking for, and in many cases receiving, direct support from their readers in the form of subscriptions, donations, and other revenue streams that might replace the declining advertising revenue from their print and broadcast properties. ${ }^{69}$ Almost in the way that the media critic Jean Baudrillard once claimed that Disneyland, with its simulations of Main Street USA and other fantastical, nostalgic spaces, provided an alibi or sense of reassurance that the real world outside the park still existed, these fake news websites and the paranoia and suspicion that they have engendered seem to have given traditional media a new aura of authenticity and importance. ${ }^{70}$

\section{CONCLUSION}

While the 2016 election and the surprise victory of Donald Trump may have been a shocking event that "shook the foundations of American politics," two of its most notable features - the cloud of suspicion and conspiratorial theorizing under which it unfolded and the reemergence of "fake news" - were the products of longstanding trends in American culture and its media. ${ }^{71}$ The political backdrop-and, I would argue, accelerating cause-of these larger shifts was of course the war on terror. As the US government's response to 9/11 began to accentuate the political polarization and partisan infighting of the late 1990s, it also generated policies and practices seemingly designed to bear out, or perhaps simply validate, the darkest fears of the conspiracy community. These included things like CIA black sites, extraordinary rendition, John Poindexter's Total Information Awareness program, and at least rumors of the widespread surveillance practices that were eventually revealed by Edward Snowden. Snowden of course provided only one in a long line of explosive leaks that included those of WikiLeaks, of the Abu Ghraib images, and several other such leaks that quickly took on a role as fodder for conspiracy media in an ever-widening landscape of attempts to contain and explain the causal logic of these events. This culture of suspicion, and the perceived failure of traditional news outlets to adequately account for and address these events, in turn fueled the rise of the midstream news outlets discussed here.

In the early phases of the war on terror, political activists and independent documentary filmmakers responded by utilizing newly available and rapidly evolving digital tools and channels of distribution as they sought to expose and condemn what many deemed to be an ill-conceived, unjust response to the terrorist attacks on September 11, 2001. The election of a progressive president on a netroots wave of enthusiasm touting a platform of "hope and change" brought with it the mainstream institutionalization of some of these technologies. These promises were further challenged by political activists and journalists seeking total transparency. The election of Donald Trump on a surge of nationalist populism not 
only redefined the political right in the United States but also demonstrated the extent to which the politics of opposition and the ethos of technological disruption had become part of the mainstream political discourse. By 2016, many of the tools utilized in these early official and oppositional responses to the war on terror (social networking, user-generated content, virtual simulation, data visualization) had become mainstream platforms in themselves. Just as sound technology or observational footage had evolved from cutting-edge, novel approaches into standard elements in the documentary lexicon, these new technologies became established frameworks for representing the world and distributing information. Where 2016 might have betrayed the seemingly democratizing, progressive potential that (some believed) was endemic to distributed digital technology, it also demonstrated that these newly evolved representational technologies were media like any other-media capable of both transparency and obfuscation, individual expression and mass manipulation, documentary alongside fiction. They had become a space, in short, where truth lies. 